\title{
Combining in the melt physical and biological properties of poly(caprolactone) and chlorhexidine to obtain antimicrobial surgical monofilaments
}

\author{
R. Scaffaro • L. Botta • M. Sanfilippo • G. Gallo • G. Palazzolo • A. M. Puglia
}

Received: 30 May 2012 / Revised: 2 July 2012 / Accepted: 3 July 2012 / Published online: 21 July 2012

(C) Springer-Verlag 2012

\begin{abstract}
Bacterial infections on a sutured wound represent a critical problem, and the preparation of suture threads possessing antimicrobial properties is valuable. In this work, poly(caprolactone) (PCL) monofilaments were compounded at the concentration of 1,2 and $4 \%(w / w)$, respectively, to the antiseptic chlorhexidine diacetate (CHX). The incorporation was carried out in the melt by a single-step methodology, i.e. "online" approach. Mechanical tests revealed that the incorporation of $\mathrm{CHX}$ does not significantly change tensile properties of PCL fibres as the thermal profile adopted to prepare the compounded fibres does not compromise the antibacterial activity of CHX. In fact, CHX confers to compounded PCL fibres' antimicrobial property even at the lowest CHX concentration as revealed by microbiological assays performed on Escherichia coli, Micrococcus luteus and Bacillus subtilis strains. The scanning electron microscope micrographs and energy-dispersive X-ray analysis of compounded threads revealed that CHX is uniformly distributed on fibre surface and that the overall amount of superficial $\mathrm{CHX}$ increases by increasing compounded
\end{abstract}

Electronic supplementary material The online version of this article (doi:10.1007/s00253-012-4283-x) contains supplementary material, which is available to authorized users.

R. Scaffaro $(\bowtie) \cdot$ L. Botta $\cdot$ M. Sanfilippo

Dipartimento di Ingegneria Civile, Ambientale, Aerospaziale, dei Materiali, Università di Palermo,

Viale delle Scienze,

90128 Palermo, Italy

e-mail: roberto.scaffaro@unipa.it

G. Gallo · G. Palazzolo • A. M. Puglia

Dipartimento di Scienze e Tecnologie Molecolari e Biomolecolari,

Università di Palermo,

Viale delle Scienze,

90128 Palermo, Italy
CHX concentration. This distribution determines a biphasic CHX release kinetics characterized by an initial rapid solubilisation of superficial CHX micro-crystals, followed by a slow and gradual release of CHX incorporated in the bulk. Interestingly, the compounded threads did not show any toxic effect compromising cell viability of human fibroblasts in vitro, differently from that observed using an equal amount of pure CHX. Thus, this study originally demonstrated the effectiveness of an "online" approach to confer antimicrobial properties to an organic thermoplastic polymeric material commonly used for medical devices.

Keywords Antimicrobial filaments · Chlorhexidine · Melt processing $\cdot$ Poly(caprolactone)

\section{Introduction}

Bacterial contamination is a problem that concerns a wide variety of materials used for biomedical applications. Generally, an alien material in the body provokes an immune and/or inflammatory response at different intensity levels. This is particularly true for surgical suture threads. In contact with the wound, suture threads are quickly coated with proteins-rich fluids, like fibrinogen and fibronectin, which create the ideal environment for the proliferation of microorganisms infecting the surgical site. The bacterial infection in the contaminated suture triggers immune system cells, usually granulocytes, that may be ineffective to contrast the infection and that result in local inflammatory reaction (Masini et al. 2011). Thus, additional therapies based on antibiotics and anti-inflammatory drugs are often required determining a further systemic burden, due to physiological detoxification and/or side effects, and even 
an increment of healthcare costs (Leaper et al. 2011). Alternatively, the active drug could be part of the suture thread, being effective on-site reducing systemic consequences. Providing a suture thread or, generally, a polymeric article with antimicrobial properties can be achieved by different routes (Kenawy et al. 2007; Zhukovskii et al. 2007).One approach is to provide the polymer with antimicrobial properties in an "offline" preparation process. In this case, the thread is superficially coated using a specific antimicrobial component previously dissolved in a solvent (Blaker et al. 2004; Dubas et al. 2011; Harnet et al. 2009; Gupta et al. 2007, 2008; Pollini et al. 2009; Saxena et al. 2011; Zurita et al. 2006). Another approach is to add the biocide agent in the polymers "online", i.e. during either the preparation/forming in solution (Hu et al. 2010; Liu et al. 2010) or in the melt (Douglas et al. 2010; Nostro et al. 2010, 2012; Perale et al. 2010; Scaffaro et al. 2011, 2012). Online methods are preferred because the processing temperatures to synthesize or melt polymers are usually lower than the decomposition/deactivation temperature of the antimicrobial agent. Furthermore, melt processing has the advantage to use equipment commonly used to process thermoplastic materials, thus ensuring large production volumes and solventless environments. Therefore, the overall environmental impact is decreased, the costs reduced and the presence of solvents/by-products in the thread which can then be absorbed by the organism minimized. Poly(caprolactone) (PCL) is an aliphatic synthetic biodegradable polyester, frequently used in biomedical applications for drug controlled release (Douglas et al. 2010; Guillaume et al. 2011; Luong-Van et al. 2006; Teo et al. 2011), absorbable suture threads (Barber and Click 1992; Charuchinda et al. 2003; Liu et al. 2010; Perale et al. 2010) and tissue engineering (Choong et al. 2012; Croisier et al. 2012; Li et al. 2003).

Chlorhexidine (CHX) is an antibacterial agent active to both Gram-positive and Gram-negative bacterial strains as well as to fungi in a dose-dependent manner (McDonnell and Russell 1999; Russell and Day 1993). It is usually used for its antiseptic and disinfectant action on wounds, in several products for oral protection and, in general, for dentistry applications (Arnold et al. 2008; Fong et al. 2010; Hiraishi et al. 2008; Huynh et al. 2010; Leung et al. 2005).

In order to prepare monofilaments to be applied as threads for surgical sutures and possessing antimicrobial properties, an "online" method was used to combine the physicochemical and biological property of PCL and CHX, respectively. The effect of CHX amount on the antimicrobial properties, release kinetic and on the mechanical performance was tested by using microbiological and chemical-physical methodologies. In addition, a possible toxic effect of compounded threads on human cells was evaluated in vitro by monitoring cell viability.

\section{Materials and methods}

Materials and preparation

PCL $\left(\mathrm{Mn}=70,000-90,000 \mathrm{gmol}^{-1}\right.$ by $\mathrm{GPC}, \mathrm{Tm}=60{ }^{\circ} \mathrm{C}$, density $=1.145 \mathrm{~g} / \mathrm{ml}$ at $25^{\circ} \mathrm{C}$ ) and $\mathrm{CHX}$ (chemical formula: $\mathrm{C}_{22} \mathrm{H}_{30} \mathrm{Cl}_{2} \mathrm{~N}_{10} \cdot\left(\mathrm{C}_{2} \mathrm{H}_{4} \mathrm{O}_{2}\right)_{2}, \mathrm{Tm}=155^{\circ} \mathrm{C}$, water solubility= $19 \mathrm{mg} / \mathrm{ml}$ ) were purchased from Sigma-Aldrich.

CHX was added to PCL at 1,2 and $4 \%(w / w)$ at the solid state, and then the mixture was fed to a counter-rotating twin screw compounder (Brabender, $D=45 \mathrm{~mm}, L / D=7$ ) with a thermal profile of $40-50-70-100^{\circ} \mathrm{C}$ and a speed of $64 \mathrm{rpm}$. In order to prevent hydrolytic scissions during processing, PCL was dried under vacuum at $40{ }^{\circ} \mathrm{C}$ for about $24 \mathrm{~h}$ according to previous studies (Charuchinda et al. 2003; Perale et al. 2010).

PCL and PCL/CHX blends were spun after drying at $40{ }^{\circ} \mathrm{C}$ for $6 \mathrm{~h}$ by using a capillary rheometer (Rheoscope 1000 , CEAST Italy) equipped with a capillary having $D=$ $1 \mathrm{~mm}$ and $L / D=40$. More in detail, a piston pressed the molten polymer from a cylindrically shaped reservoir to the capillary above described. At the exit of the capillary, the filament was drawn at constant speed and free cooling at room temperature using a collecting pulley rotating at $10 \mathrm{rpm}$. Under these conditions, the threads had a diameter of $300 \pm 10 \mu \mathrm{m}$.

\section{Characterization of CHX-compounded PLC fibres}

\section{Morphology}

The morphology of the fibres and of neat CHX was analyzed by a scanning electron microscope (SEM) (Quanta 200F ESEM, FEI, Hillsboro, USA). All samples were sputter-coated with a thin layer of gold to avoid electrostatic charging under the electron beam. Moreover, energydispersive X-ray (EDX) analysis was performed on some samples with the same apparatus.

\section{Mechanical characterization}

Tensile tests (ASTM D882) of fibres (at least seven replicates) were carried out by using a dynamometer (Instron Model 3365, Instron, UK). The grip distance was $30 \mathrm{~mm}$, while the tensile speed was $1 \mathrm{~mm} / \mathrm{min}$ for the first $2 \mathrm{~min}$ and $100 \mathrm{~mm} / \mathrm{min}$ thereafter. The data are reported as means $\pm \mathrm{SD}$.

\section{CHX release}

A series of CHX solutions of distilled water containing 0.1 thru $1.5 \mathrm{mg} / \mathrm{dL}$ of CHX was used to obtain a calibration curve correlating the absorbance peak intensity and the CHX concentration using a UV/vis spectrophotometer 
(model UVPC 2401, Shimadzu Italia s.r.l., Milan, Italy). In the concentration range here investigated, the calibration curve was found to be a line (Supplementary Fig. S1). The maximum absorbance peak of CHX was detected at $260 \mathrm{~nm}$ in full accordance with the scientific literature (Hiraishi et al. 2008). The release of CHX from the fibres was investigated by immersing a pre-weighed sample (approximately $12 \mathrm{mg}$, $14 \mathrm{~cm}$ long) in $8 \mathrm{ml}$ of distilled water. At specific time intervals, the absorbance peak intensity at $260 \mathrm{~nm}$ of the storage solutions was measured and converted to the quantities of CHX released based on the calibration line. After each measurement, the samples were immersed in $8 \mathrm{ml}$ of fresh distilled water, and the cumulative release of $\mathrm{CHX}$ here reported was calculated by sequentially adding the CHX released after each step.

\section{Microbiological assays}

Micrococcus luteus ATCC 10240, Bacillus subtilis ATCC 6633 and Escherichia coli DH5 $\alpha^{\mathrm{TM}}$ (Invitrogen) were used as tester strains.

\section{Agar diffusion tests}

For each tester strain, a bacterial suspension of $10^{8}$ colonyforming units (CFU) was inoculated into $5 \mathrm{ml}$ of $\mathrm{LB}$ soft
Fig. 1 SEM micrographs of filament surfaces at two different magnifications: $\mathbf{a}, \mathbf{b}$ PCL $+1 \%$ CHX; c, d PCL + $2 \%$ CHX; e, f PCL $+4 \%$ CHX
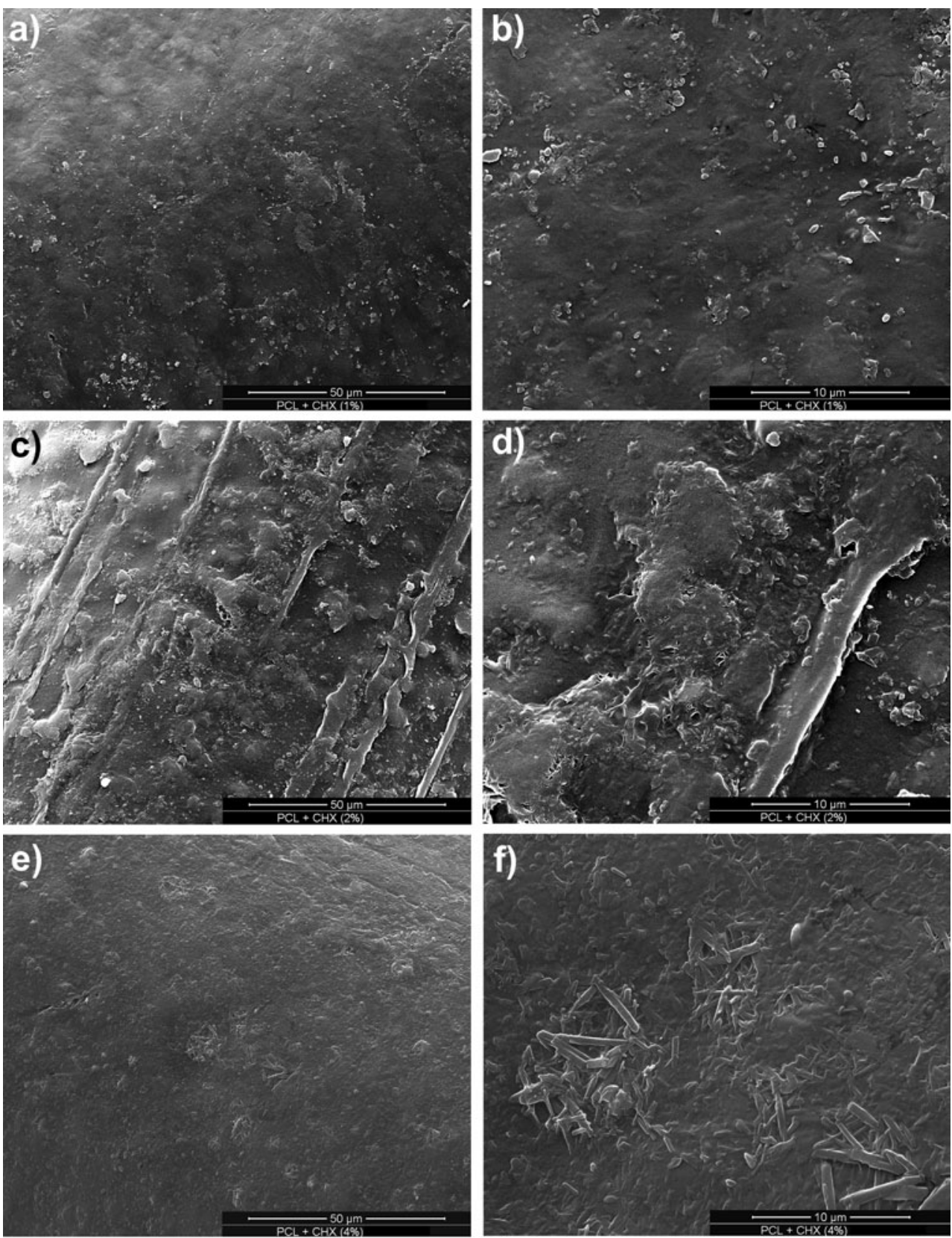
agar to obtain a uniform bacterial overlay on LB agar plates. PCL fibres containing CHX at 1,2 and $4 \%(w / w)$ were placed over tester overlay. Neat PCL fibres, discs of 3-mm paper (Whatman) imbibed by $10 \mu \mathrm{g}$ of pure CHX or $10 \mu \mathrm{g}$ of pure CHX treated for $2 \mathrm{~min}$ at $100{ }^{\circ} \mathrm{C}$ were used as controls. Growth inhibition halos were observed after overnight incubation at $37^{\circ} \mathrm{C}$.

\section{Colony-forming unit plate counting}

For each tester strain, $2 \mathrm{ml}$ of $\mathrm{LB}$ broth containing a bacterial suspension at the concentration of $10^{6} \mathrm{CFU} / \mathrm{ml}$ was incubated in sterile test tubes with $2 \mathrm{mg}$ PCL fibres containing $\mathrm{CHX}$ at 1,2 and $4 \%$. Parallel control cultivations were performed without PCL fibres or adding: neat PCL fibres, $10 \mu \mathrm{g} / \mathrm{ml}$ of pure CHX or $10 \mu \mathrm{g} / \mathrm{ml}$ of pure CHX treated for $2 \mathrm{~min}$ at $100{ }^{\circ} \mathrm{C}$. After 18 and $24 \mathrm{~h}$ of incubation at $37{ }^{\circ} \mathrm{C}$ in an orbital shaker $(200 \mathrm{rpm})$, the number of bacterial viable cells was determined by plating aliquots of $100 \mu \mathrm{l}$ of serial dilutions on LB agar plates and incubating overnight at $37{ }^{\circ} \mathrm{C}$ for $\mathrm{CFU}$ counting.

\section{Toxicity tests}

\section{Human fibroblast culture}

Human IMR90 fibroblasts (ATCC CCL-186) were used as tester cells to evaluate toxicity of CHX-embedded PCL fibres. Cells were seeded in $24-w e l l$ plates $\left(10^{4}\right.$ cells/well $)$ and cultured in a humidified incubator with $5 \% \mathrm{CO}_{2}$ at $37{ }^{\circ} \mathrm{C}$ using $2 \mathrm{ml}$ Minimum Essential Medium (Sigma) supplemented with $10 \%$ foetal bovine serum (Gibco, EU approved, Invitrogen, Italy), $2 \mathrm{mM}$ L-glutamine, $100 \mathrm{U} / \mathrm{ml}$ penicillin, $0.1 \mathrm{mg} / \mathrm{ml}$ streptomycin, $1 \mathrm{mM}$ sodium pyruvate and non-essential amino acids (Invitrogen, Italy). Four-day grown cells at about $80-90 \%$ of confluence were then incubated for $24 \mathrm{~h}$ in the presence of $2 \mathrm{mg}$ PCL fibres compounded with $4 \% \mathrm{CHX}$ and tested for viability. As the control, cells were incubated in the absence of PCL fibre or in the presence of: neat PCL fibre, pure CHX $(40 \mu \mathrm{g} / \mathrm{ml})$ or pure $100{ }^{\circ} \mathrm{C}$-treated $\mathrm{CHX}(40 \mu \mathrm{g} / \mathrm{ml})$. Each cultivation was performed in quadruplicate.

\section{Viable cell determination by differential fluorescent staining assay}

Cell viability and integrity was tested by a combination of two fluorescent DNA-binding dyes, acridine orange and ethidium bromide (AO/EB), as previously described (Martin and Leonardo 1994). In brief, $24 \mathrm{~h}$ after $4 \%$ CHX PCL fibre exposure, spent medium was removed, and cells were stained with a $100-\mu \mathrm{l}$ AO/EB mixture, each at a concentration of $100 \mu \mathrm{g} / \mathrm{ml}$ in phosphate-buffered saline (PBS). The differential uptake of the two dyes allowed the identification of viable and non-viable cells by fluorescence microscopy. Acridine orange permeates throughout the cells and renders the nuclei bright green. Ethidium bromide penetrates slowly intact cells, while it is rapidly uptaken by cells whose cytoplasmic membrane integrity is compromised, and thus, it stains the nuclei bright red. Cells from duplicated parallel cultivations were observed by fluorescence inverted microscopy (Axio, USA), and images were analyzed by Vision software (Axio). For quantitative analysis, cell fields were randomly chosen, and five images were analysed for each well. The
Fig. 2 Cumulative CHX release expressed as micrograms per milligram of filaments containing different concentrations of CHX

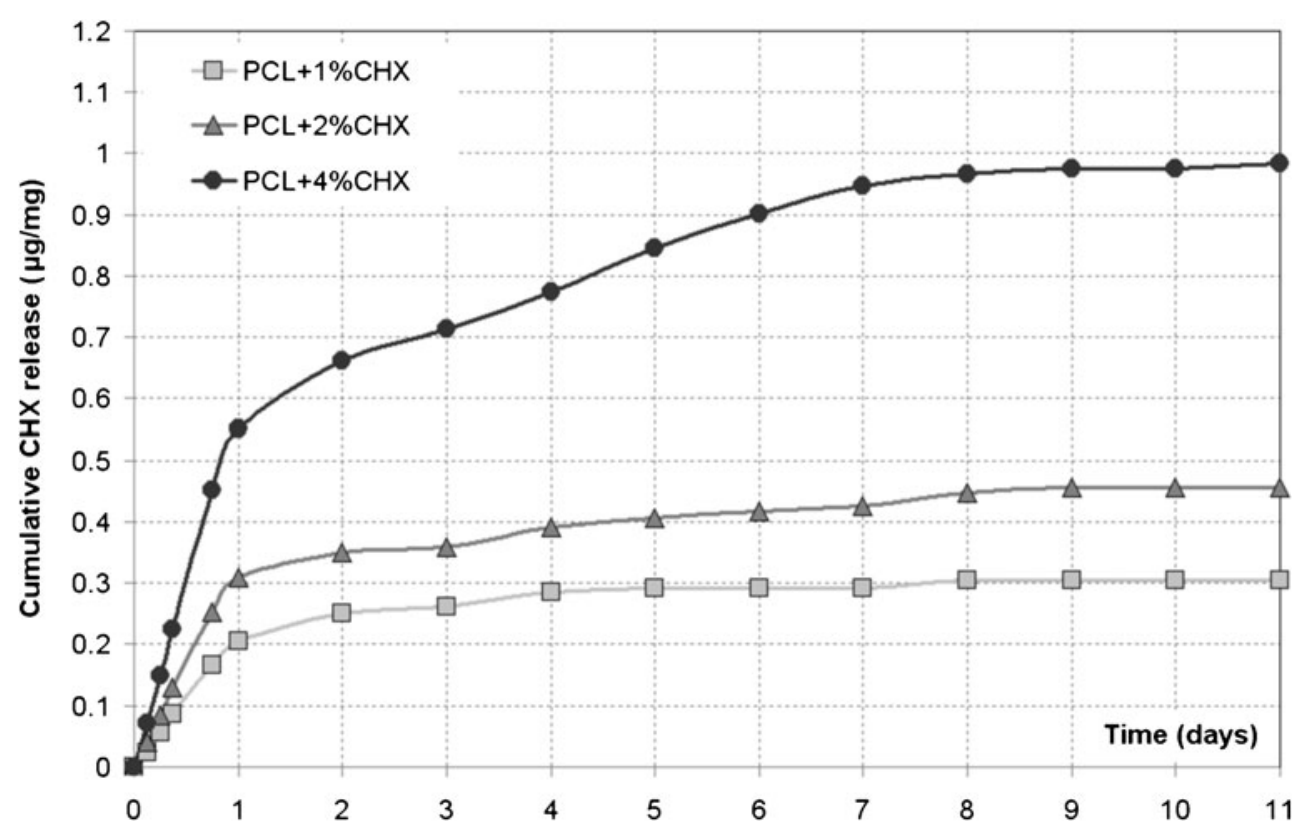


Fig. 3 SEM micrographs together with the EDX spectra of the $4 \%$ CHX-compounded PCL filament (a) and after (b) 7 days of storage in distilled water
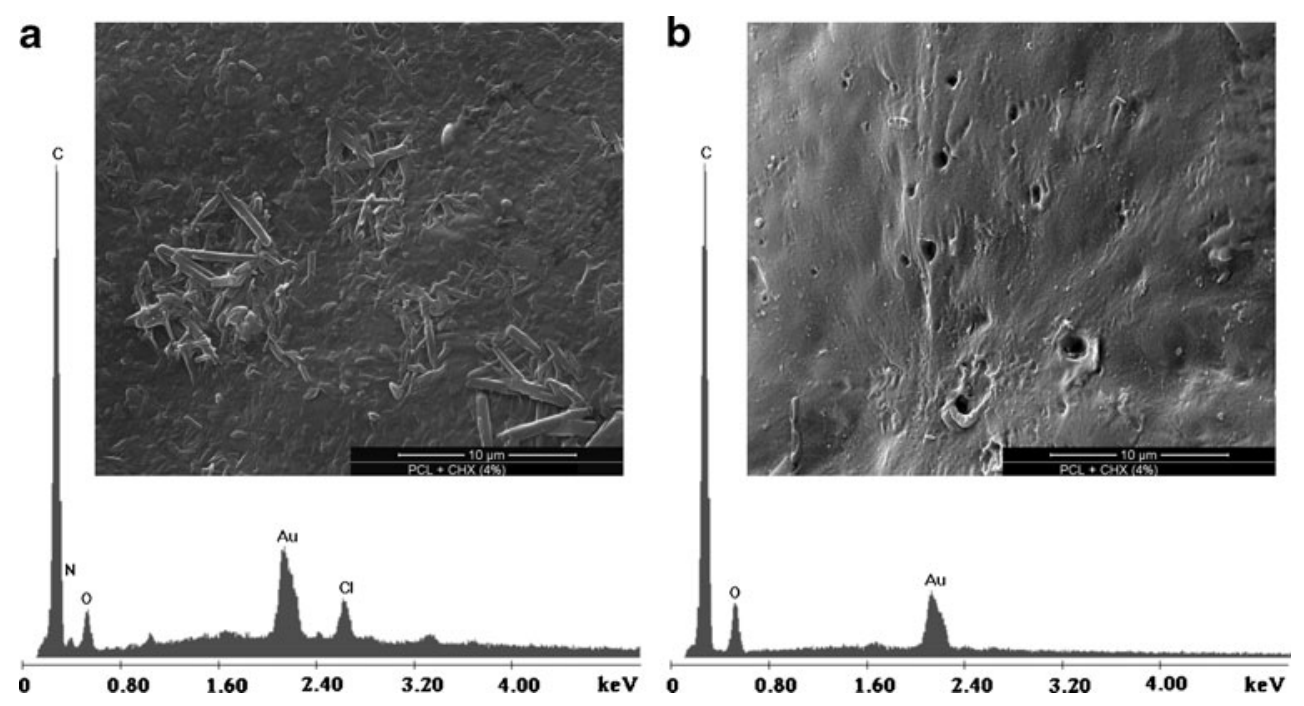

values are shown as ratio of viable /total cells, and data are reported as means $\pm \mathrm{SD}$.

\section{Viable cell counting by trypan blue exclusion assay}

Cell viability was further quantitatively determined by trypan blue exclusion assay (Mishell and Shiigi 1980). After $24 \mathrm{~h}$ of $4 \%$ CHX PCL fibre exposure, cells were collected by trypsinization and stained with $0.4 \%$ trypan blue solution in PBS. Viable versus total cells, from duplicated parallel cultivations, were manually counted in a hemocytometer under an inverted light microscope with $\times 20$ magnification. The trypan blue dye is normally taken up by non-viable cells but not by viable cells because it only penetrates through damaged cellular membranes. Cell viability was calculated as the percentage of viable cells compared to the total number of counted cells. Three independent counts were performed for each cultivation, and data are reported as means $\pm \mathrm{SD}$.

\section{Results}

Morphological and physical characterization of CHX-compounded PCL fibres

CHX was compounded to PCL at the concentrations of 1,2 and $4 \%(w / w)$ by using a counter-rotating twin screw compounder. Spun threads were then obtained by using a capillary rheometer (See Supplementary Fig. S2 for the morphology of neat PCL). CHX additive forms crystalline aggregates uniformly on the surface of the compounded PCL threads at all the three CHX concentrations as SEM micrographs revealed (Fig. 1; Supplementary Fig. S3). In particular, the overall amount of superficial CHX increases by increasing CHX concentration, and at the highest concentration, a crowded pattern of crossed CHX microcrystals occurs (Fig. 1f).

In order to investigate the relationship between surface distribution and CHX release in an aqueous solution, release
Fig. 4 Elastic modulus (E), tensile stress (TS) and elongation at break $(E B)$ of all the filaments prepared

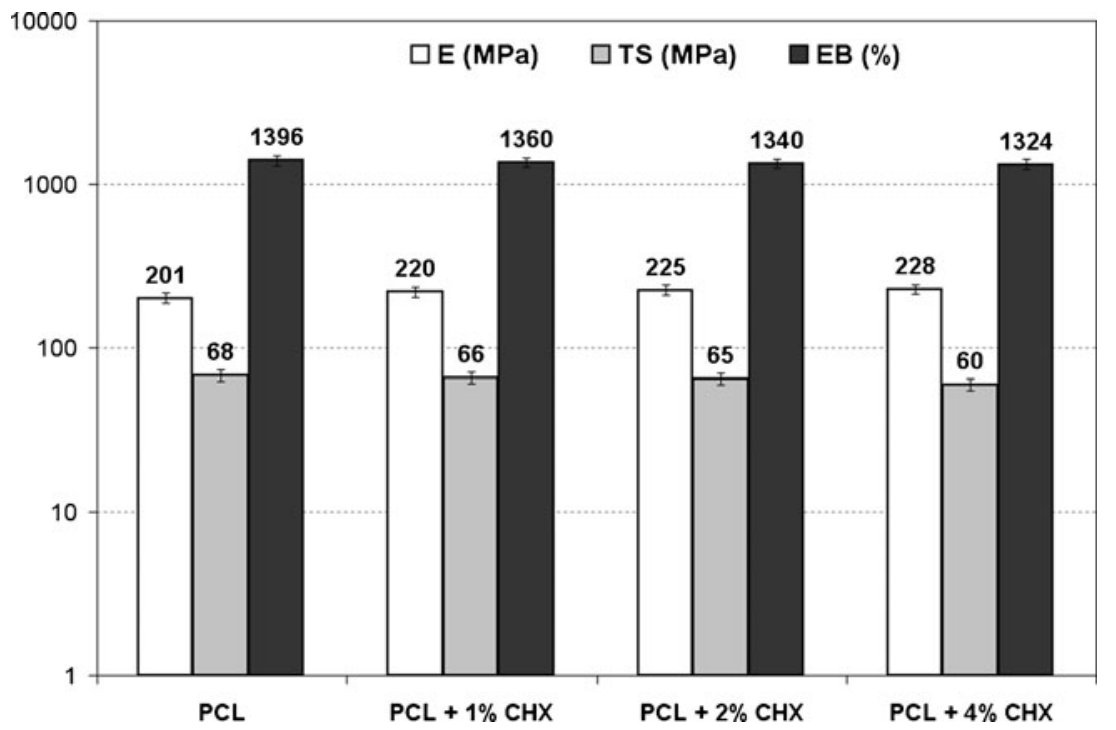


Fig. 5 Agar diffusion test performed on $M$. luteus overlay. PCL fibres containing CHX at 1,2 and $4 \%(w / w)$ were placed over tester overlay. Bacterial growth inhibition halos were observed around all CHXcompounded PCL fibres after an overnight incubation at $37^{\circ} \mathrm{C}$. Neat PCL fibres, discs of 3-mm paper imbibed by $10 \mu \mathrm{g}$ of pure $\mathrm{CHX}$ or $10 \mu \mathrm{g}$ of pure $\mathrm{CHX}$ treated at $100{ }^{\circ} \mathrm{C}$ pure CHX were used as controls. Similar results were obtained for E. coli and B. subtilis used as tester strains (data not shown)

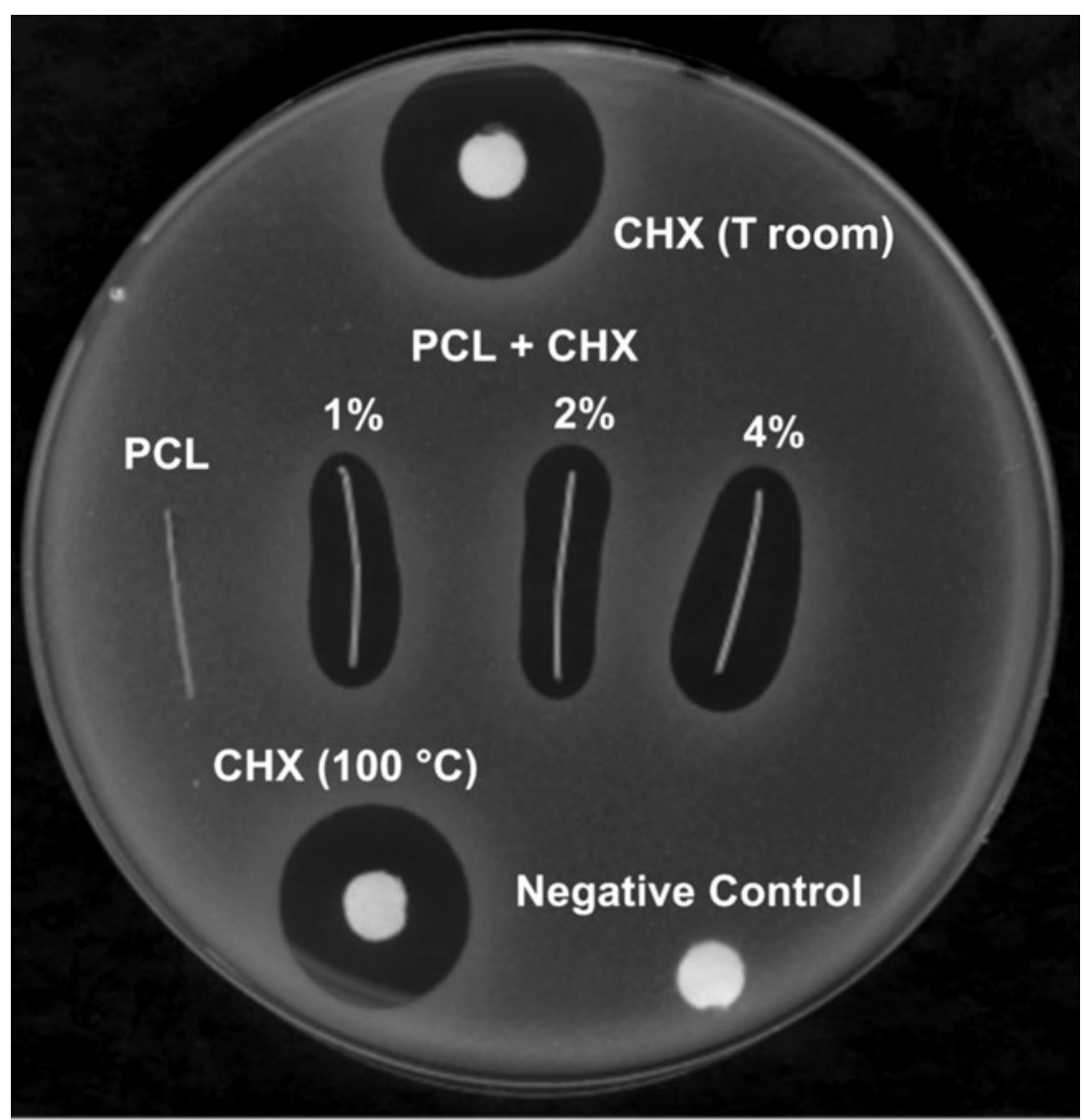

kinetics in distilled water was measured (Fig. 2). According to the CHX surface distribution, increasing $\mathrm{CHX}$ amount in the compounded fibres led to an increased $\mathrm{CHX}$ release during time. Thus, the higher availability of $\mathrm{CHX}$ on the thread surface of the fibres containing $4 \%$ of $\mathrm{CHX}$ results in a higher amount of ready-to-be solubilized compound. This result was further confirmed by SEM analysis together with the EDX spectra of a $4 \%$ CHX thread untreated (Fig. 3a) and after 7 days of immersion in distilled water (Fig. 3b). In fact, the EDX spectrum of untreated threads shows the
Fig. 6 M. luteus cultivations in liquid broth after a 24-h exposure to CHX-compounded PCL

fibres. The fibres were immersed in a liquid medium containing a starting number of $10^{6}$ bacteria $/ \mathrm{ml}$. Similar results were obtained for E. coli and B. subtilis (data not shown)

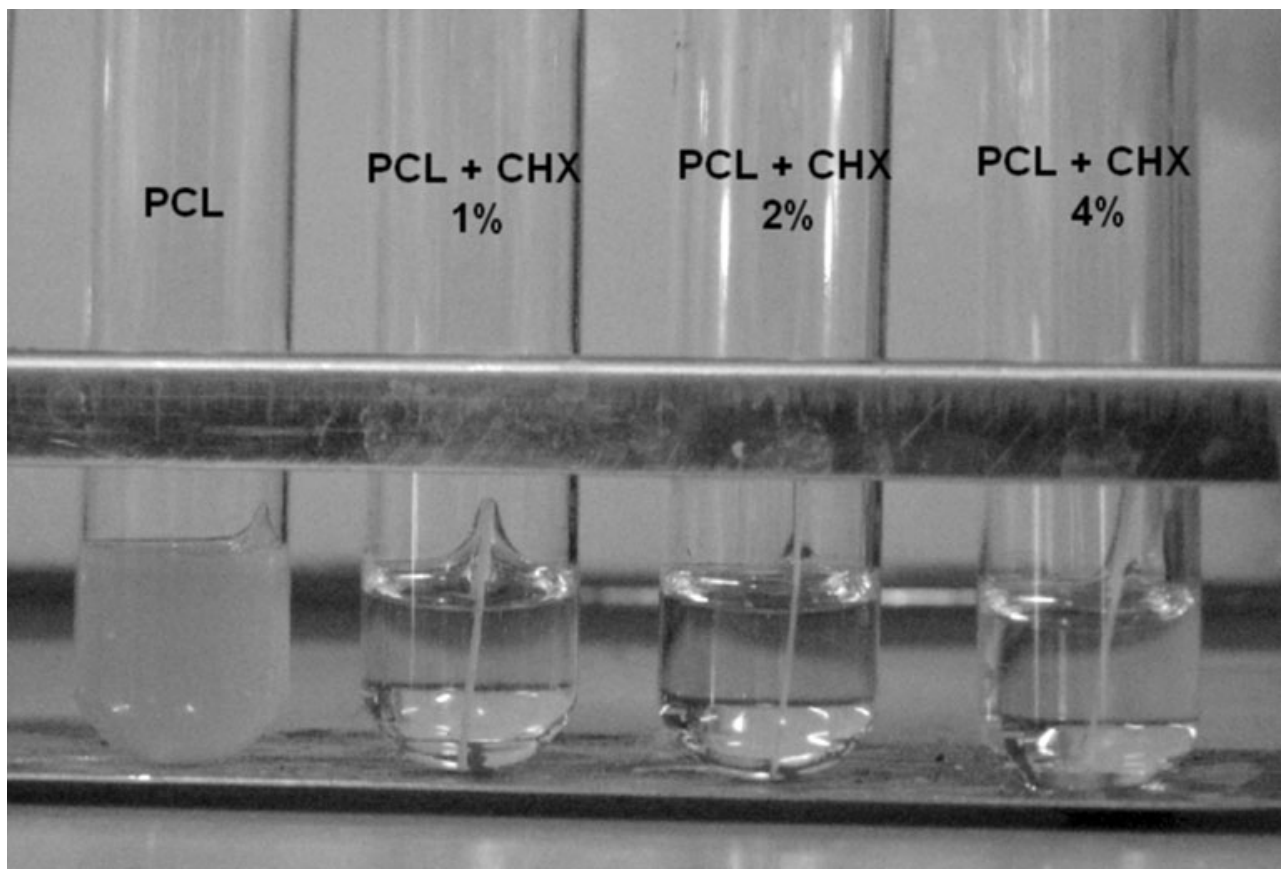


presence of $\mathrm{N}$ and $\mathrm{Cl}$ (Fig. 3) due to superficial $\mathrm{CHX}$ as SEM micrograph and the comparison with the EDX spectrum of neat CHX reveals (Supplementary Fig. S4). After 7 days of immersion in water, the EDX spectrum does not show the presence of $\mathrm{N}$ and $\mathrm{Cl}$, and in the SEM micrographs, there are evident cavities, likely to be due to $\mathrm{CHX}$ micro crystals leached during immersion in water.

In order to verify if the CHX incorporation caused some modification of the mechanical performance of the materials, thus inhibiting or reducing the possible practical use, tensile mechanical testing was performed, Fig. 4. This analysis revealed that the observed variation of the elastic modulus (E), the tensile stress (TS) and the elongation at break (EB) of all the compounded threads are very small even at the highest $\mathrm{CHX}$ concentration used. In particular, the increase of CHX content coincides with a slight increase of $E$ and a slight decrease of TS and EB parameters. Anyway, these variations (about $12 \%$ at last) are small and have poor significance in terms of mechanical performance variations.

\section{Antimicrobial activity of CHX-compounded PCL fibres}

The presence of CHX on the polymer surface is compatible with potential antimicrobial activity of the fibres. To verify biological property, agar diffusion tests were performed using the compounded spun fibres against three tester strains, the Gram-positive M. luteus and B. subtilis and the Gram-negative E. coli, which are reported to be sensitive to chlorhexidine (Dance et al. 1987; Hammond et al. 1987). The presence of inhibition growth halos was observed for all the three tester strains around spun fibres compounded with 1, 2 and 4 CHX (Fig. 5). In addition, inhibition zone areas around 1 and $2 \%$ CHX-compounded fibres seemed similar, while a net enlargement of inhibition zone was observed using $4 \%$ CHX spun fibres. Therefore, this analysis suggests that 1 and $2 \% \mathrm{CHX}$ fibres release a similar antibiotic amount, while $4 \%$ CHX spun fibres release an increased amount of antibiotic. This evidence is in agreement with the results of CHX release kinetics (Fig. 2).

Moreover, the CHX used as positive control showed no or negligible change of the inhibition halo after a thermal treatment at $100{ }^{\circ} \mathrm{C}$ for $2 \mathrm{~min}$, i.e. under the same conditions adopted to prepare the threads.

Furthermore, in order to perform the counting of viable bacterial cells after CHX-compounded fibre exposure, the fibres were immersed in liquid cultures. In particular, bacterial cultivations were performed inoculating separately the tester strains in the presence of the three kinds of CHXcompounded spun fibres, respectively (Fig. 6). The quantitative data obtained by counting the number of bacterial viable cells as CFU after 18- and 24-h exposure to CHXcompounded PCL fibres showed a drastic decrease of the number of viable cells in all cultivations containing 1,2 and
$4 \%$ CHX spun fibres in respect of starting amount of inoculated bacteria (Fig. 7). This is consistent with the bactericidal effect of CHX released by compounded PCL fibres on all tester strains. Actually, it can be also observed that even if the growth inhibition is evident at all the

a

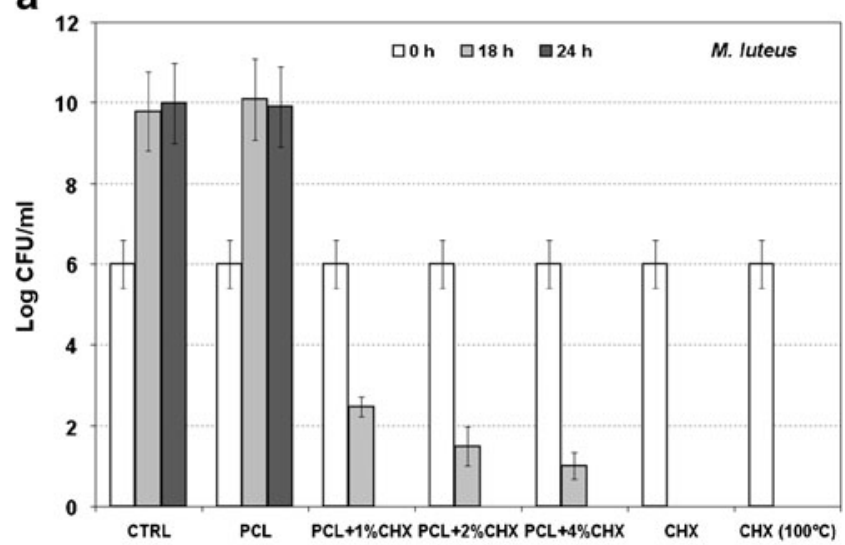

b

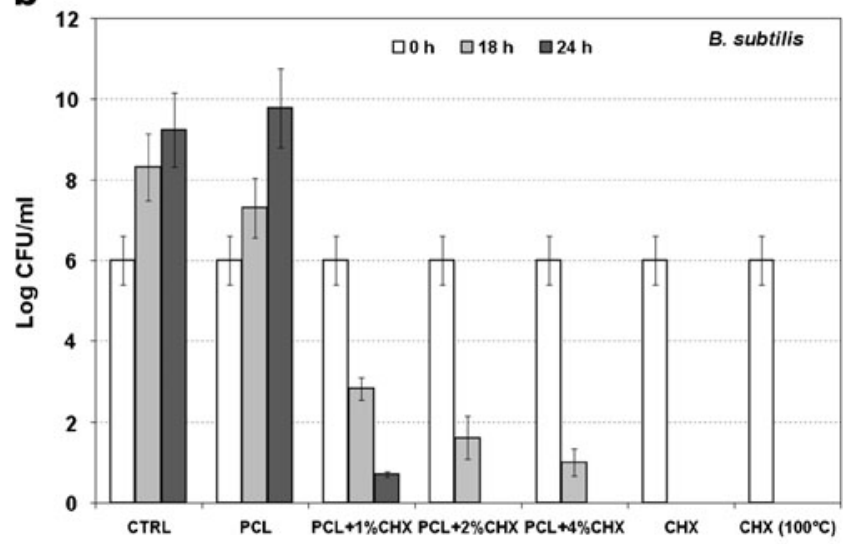

C

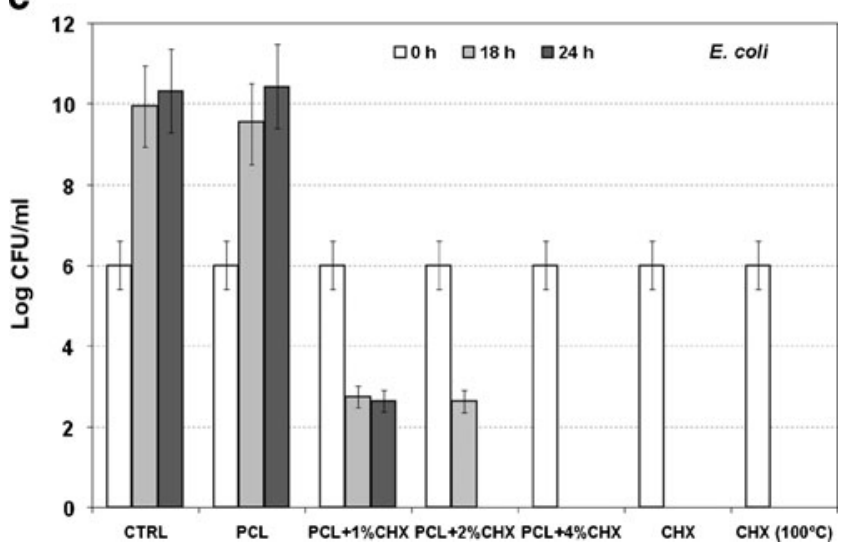

Fig. 7 Counting of bacterial viable cells as colony-forming units (CFU). After 18- and 24-h exposure to CHX-compounded PCL fibres, 100- $\mu$ l aliquots from serial dilutions of M. luteus, B. subtilis and E. coli cultivations were plated on LB agar medium, respectively. After an overnight incubation at $37{ }^{\circ} \mathrm{C}$, the total number of colonies was counted and reported as CFU per millilitre 
concentrations, the fibres containing $4 \% \mathrm{CHX}$ display the best and fastest activity if compared with those containing 1 or $2 \%$ of additive likely because of the different release kinetics of CHX.

Toxic effect in vitro evaluation of CHX-compounded PCL fibres on human cells

In order to assess the possible effects of CHX-compounded spun fibres on human cells, cell viability in vitro assays were performed. For this purpose, human fibroblast IMR90 cells, routinely used as tester cell line for toxicity assays, were exposed for $24 \mathrm{~h}$ to $4 \% \mathrm{CHX}$ spun fibres (AshaRani et al. 2009; Oh et al. 2010). In parallel, cells incubated with/without neat spun PCL fibres were used as negative controls, while cells maintained in the presence of pure $\mathrm{CHX}$ or $100{ }^{\circ} \mathrm{C}$-treated $\mathrm{CHX}$ (the same amount of the one incorporated in $4 \% \mathrm{CHX}$ fibres used in this experiment) were used as positive controls.

Interestingly, trypan blue exclusion assay revealed that $4 \%$ CHX spun fibre exposure does not impair cell viability in comparison with the negative controls, while exposure to pure $\mathrm{CHX}$ or $100{ }^{\circ} \mathrm{C}$-treated $\mathrm{CHX}$ reduces cell viability to $1 \%$ (Fig. 8), accordingly to what has been reported in previous studies (Chang et al. 2001; Hidalgo et al. 2001). This result was confirmed by cell morphology and integrity inspection based on differential AO/EB staining. In particular, Fig. 9a indicates that cell morphology and ethidium bromide penetration into human cells exposed to $4 \%$ CHXcompounded fibres are similar to the negative controls. On the other hand, severe damages, necrotic morphology and high penetration of ethidium bromide were revealed in cells incubated in the presence of $\mathrm{CHX}$ and $100{ }^{\circ} \mathrm{C}$-treated $\mathrm{CHX}$. In fact, $4 \% \mathrm{CHX}$ spun fibre does not exert toxic effects on cell viability. Quantitative data from AO/EB-stained cells are essentially in agreement with trypan blue exclusion assay results, showing, respectively, 96, 97 and $95 \%$ of cell integrity in negative control and cells exposed to neat and $4 \%$ CHX spun fibres (Fig. 9b). Furthermore, no intact cells were revealed after exposure to pure $\mathrm{CHX}$ or $100{ }^{\circ} \mathrm{C}$-treated CHX.

\section{Discussion}

To the best of our knowledge, this study demonstrated for the first time the effectiveness of an "online" approach to confer antimicrobial properties to an organic thermoplastic polymeric material commonly used for medical devices. CHX-compounded PCL fibres were found to combine the physical-chemical and biological properties of PCL, a low-melting point polymeric material, and of $\mathrm{CHX}$, a potent antimicrobial agent, respectively. PCL and CHX were also chosen for their large use in biomedical applications; anyway, the online approach here described can be extended to prepare suture materials using different polymers to be compounded to different antimicrobial agents.

The compounded fibres acquired powerful antimicrobial activity that did not compromise the overall mechanical performance of threads. In fact, the variations in tensile properties are very small even at the highest CHX concentration used, and this is likely to be due to the good and uniform dispersion of the CHX preventing the formation of aggregates that could cause decreased mechanical properties of the threads. On the other hand, the thermal profile adopted to prepare the compounded fibres does not compromise the antibacterial activity of CHX since $100{ }^{\circ} \mathrm{C}$-treated CHX used in biological assay showed no or negligible change in comparison with non-treated CHX.
Fig. 8 Viable cell counting by trypan blue exclusion assay performed on human fibroblasts after a 24 -h exposure to $4 \%$ CHX fibres

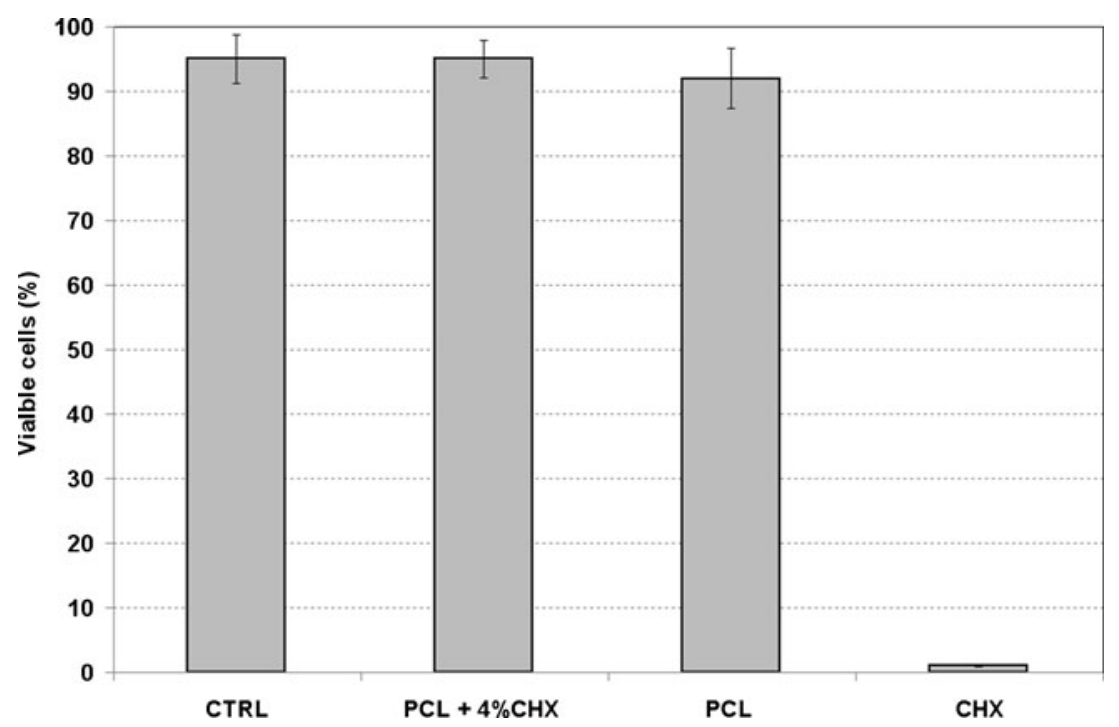



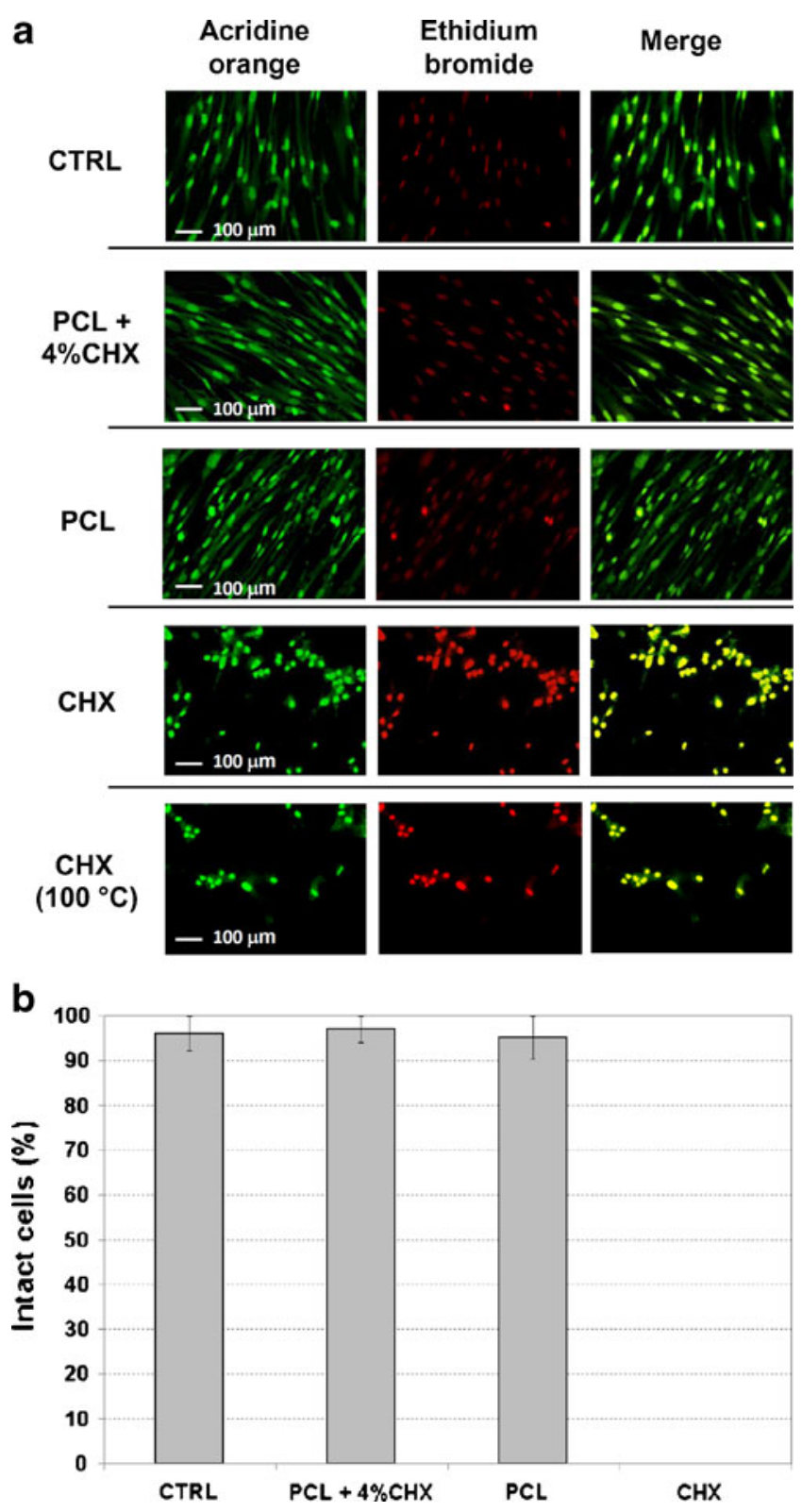

Fig. 9 Human fibroblast cell integrity by differential acridine orange/ ethidium bromide staining. a Cell morphology and ethidium bromide penetration into human cells after $24 \mathrm{~h}$ of exposure. b Quantitative data of cell integrity

The release of CHX from the monofilaments is characterized by an initial phase with a rapid solubilisation of superficial CHX micro-crystals, followed by a second phase which is characterized by a slow kinetic achieving its plateau after 1 week. The SEM micrographs of compounded threads coupled with EDX analysis revealed that CHX, incorporated in the melt, is uniformly distributed onto the fibre surface and that the overall amount of superficial CHX increases by increasing compounded CHX concentration. In fact, bacterial growth inhibition is evident at all compounded CHX concentrations with the fibres containing
$4 \%$ CHX displaying the best and fastest activity. Thus, higher availability of CHX on the thread surface results in higher amounts of ready-to-be solubilized compound. The CHX availability on the fibre surface can be probably considered the cause of the initial burst effect revealed in the kinetic release study. The second phase of CHX release may be due to a water-dependent relaxation of the PCL matrix that allows the exposition of the internal CHX. This characteristic of compounded threads may be of interest since the bursting drug release can be useful to inhibit bacterial spreading at the beginning of wound cleansing. The following phase, with a slow and progressive release of the additive, grants the extension of the antibacterial activity.

Interestingly, the threads containing the highest CHX level did not show in vitro any toxic effect compromising cell viability, differently from that observed using an equal amount of pure CHX. CHX activity is due to cytoplasmic membrane damage that leads to permeability alteration and eventually to cell death. This mode of action determines efficacy on both prokaryotic and eukaryotic cells in a dose-dependent manner (Russell and Day 1993). In particular, at concentrations of $0.1-1$ and $2-2.5 \mu \mathrm{g} / \mathrm{ml}$, chlorhexidine has a bacteriostatic effect against most Gram-positive bacteria and many Gram-negative bacteria, respectively (Dance et al. 1987; Hammond et al. 1987). At CHX concentrations of $10-20 \mu \mathrm{g} / \mathrm{ml}$ or more, a bactericidal effect can be expected as well as inhibitory growth property against yeasts (Russell and Day 1993). Studies evaluating in vitro toxicity on human cell revealed that CHX concentrations greater than $0.0001 \%$ significantly compromise cell viability after a 24-h exposure (Chang et al. 2001; Hidalgo et al. 2001). On the other hand, neither antibiotic nor toxic effect is reported for PCL. The results of trypan blue exclusion assay and cell morphology and integrity inspection based on differential AO/EB staining showed that the exposure to fibre incorporating the higher amount of CHX does not impair cell viability, while exposure to pure $\mathrm{CHX}$ or $100{ }^{\circ} \mathrm{C}$-treated $\mathrm{CHX}$ reduces cell viability to $1 \%$, accordingly to what has been reported in previous studies (Chang et al. 2001; Hidalgo et al. 2001). This finding might be due to the CHX release kinetics from compounded PCL fibres. In fact, since CHX effect on eucarya cells is dose-dependent, a gradual release could allows cells to counteract possible damages. Therefore, the use of CHX-compounded fibres may confer a real advantage over the use of an equal amount of free CHX as antiseptic following surgical sutures.

Although many aspects of the use of CHX-compounded fibres for human surgical application have not yet been clarified, this study provides promising results that need to be further corroborated. Therefore, further in vivo studies have to be performed to address the possible use of CHXcompounded PCL fibres for surgical applications. 
Acknowledgments This work was supported by INSTM and by PON01 01287 to RS and partially by the Italian Ministry of Education, University and Research (MIUR, ex $60 \%$ ) to AMP.

\section{References}

Arnold RR, Wei HH, Simmons E, Tallury P, Barrow DA, Kalachandra S (2008) Antimicrobial activity and local release characteristics of chlorhexidine diacetate loaded within the dental copolymer matrix, ethylene vinyl acetate. J Biomed Mater Res B Appl Biomater 86B:506-513

AshaRani PV, Low Kah Mun G, Hande MP, Valiyaveettil S (2009) Cytotoxicity and genotoxicity of silver nanoparticles in human cells. ACS Nano 24:279-290

Barber FA, Click JN (1992) The effect of inflammatory synovial fluid on the breaking strength of new "long lasting" absorbable sutures. Arthroscopy 8:437-441

Blaker JJ, Nazhat SN, Boccaccini AR (2004) Development and characterisation of silver-doped bioactive glass-coated sutures for tissue engineering and wound healing applications. Biomaterials 25:1319-1329

Chang YC, Huang FM, Tai KW, Chou MY (2001) The effect of sodium hypochlorite and chlorhexidine on cultured human periodontal ligament cells. Oral Surg Oral Med Oral Pathol Oral Radiol Endod 92:446-450

Charuchinda A, Molloy R, Siripitayananon J, Molloy N, Sriyai M (2003) Factors influencing the small-scale melt spinning of poly ( $\varepsilon$-caprolactone) monofilament fibres. Polym Int 52:1175-1181

Choong C, Yuan S, Thian ES, Oyane A, Triffitt J (2012) Optimization of poly( $\varepsilon$-caprolactone) surface properties for apatite formation and improved osteogenic stimulation. J Biomed Mater Res A 100A:353-361

Croisier F, Duwez AS, Jérôme C, Léonard AF, van der Werf KO, Dijkstra PJ, Bennink ML (2012) Mechanical testing of electrospun PCL fibers. Acta Biomater 8:218-224

Dance DAB, Pearson AD, Seal DV, Lowes JA (1987) A hospital outbreak caused by a chlorhexidine- and antibiotic-resistant Proteus mirabilis. J Hosp Infect 10:10-16

Douglas P, Andrews G, Jones D, Walker G (2010) Analysis of in vivo drug dissolution from PCL melt extrusion. Chem Eng J 164:359370

Dubas ST, Wacharanad S, Potiyaraj P (2011) Tunning of the antimicrobial activity of surgical sutures coated with silver nanoparticles. Colloids Surf A Physicochem Eng Asp 380:25-28

Fong N, Simmons A, Poole-Warren LA (2010) Antibacterial polyurethane nanocomposites using chlorhexidine diacetate as an organic modifier. Acta Biomater 6:2554-2561

Guillaume O, Lavigne J-P, Lefranc O, Nottelet B, Coudane J, Garric X (2011) New antibiotic-eluting mesh used for soft tissue reinforcement. Acta Biomater 7:3390-3397

Gupta B, Anjum N, Gulrez SKH, Singh H (2007) Development of antimicrobial polypropylene sutures by graft copolymerization. II. Evaluation of physical properties, drug release, and antimicrobial activity. J Appl Polym Sci 103:3534-3538

Gupta B, Jain R, Singh H (2008) Preparation of antimicrobial sutures by preirradiation grafting onto polypropylene monofilament. Polym Adv Technol 19:1698-1703

Hammond SA, Morgan JR, Russell AD (1987) Comparative susceptibility of hospital isolates of gram-negative bacteria to antiseptics and disinfectants. J Hosp Infect 9:255-264

Harnet JC, Le Guen E, Ball V, Tenenbaum H, Ogier J, Haikel Y, Vodouhê C (2009) Antibacterial protection of suture material by chlorhexidine-functionalized polyelectrolyte multilayer films. J Mater Sci Mater Med 20:185-193
Hidalgo E, Dominguez C (2001) Mechanisms underlying chlorhexidineinduced cytotoxicity. Toxicol in Vitro 15:271-276

Hiraishi N, Yiu CKY, King NM, Tay FR, Pashley DH (2008) Chlorhexidine release and water sorption characteristics of chlorhexidine-incorporated hydrophobic/hydrophilic resins. Dent Mater 24:1391-1399

Hu W, Huang Z-M, Liu X-Y (2010) Development of braided drugloaded nanofiber sutures. Nanotechnology 21:315104, art. n

Huynh TTN, Padois K, Sonvico F, Rossi A, Zani F, Pirot F, Doury J, Falson F (2010) Characterization of a polyurethane-based controlled release system for local delivery of chlorhexidine diacetate. Eur J Pharm Biopharm 74:255-264

Kenawy ER, Worley SD, Broughton R (2007) The chemistry and applications of antimicrobial polymers: a state-of-the-art review. Biomacromolecules 8:1359-1384

Leaper D, Assadian O, Hubner N-O, McBain A, Barbolt T, Rothenburger S, Wilson P (2011) Antimicrobial sutures and prevention of surgical site infection: assessment of the safety of the antiseptic triclosan. Int Wound J 8:556-566

Leung D, Spratt DA, Pratten J, Gulabivala K, Mordan NJ, Young AM (2005) Chlorhexidine releasing methacrylate dental composite materials. Biomaterials 26:7145-7153

Li W-J, Danielson KG, Alexander PG, Tuan RS (2003) Biological response of chondrocytes cultured in three-dimensional nanofibrous poly( $\varepsilon$-caprolactone) scaffolds. J Biomed Mater Res A 67:1105-1114

Liu H, Leonas KK, Zhao Y (2010) Antimicrobial properties and release profile of ampicillin from electrospun poly( $\varepsilon$-caprolactone $)$ nanofiber yarns. J Eng Fiber Fabr 5:10-19

Luong-Van E, Grøndahl L, Chua KN, Leong KW, Nurcombe V, Cool SM (2006) Controlled release of heparin from poly( $\varepsilon$-caprolactone) electrospun fibers. Biomaterials 27:2042-2050

Martin D, Leonardo M (1994) Microscopic quantitation of apoptotic index and cell viability using vital and fluorescent dyes. In: Coligan JE, Kruisbeek AM, Margulies D, Shevach EM, Strober W (eds) Current protocols in immunology. Wiley, New York, pp 3.17.1-3.17.39

Masini BD, Stinner DJ, Waterman SM, Wenke JC (2011) Bacterial adherence to suture materials. J Surg Educ 68:101-104

McDonnell G, Russell D (1999) Antiseptics and disinfectants: activity, action, and resistance. Clin Microbiol Rev 12:147-179

Mishell BB, Shiigi SM (1980) Selected methods in cellular immunology. Freeman, San Francisco, pp 16-19

Nostro A, Scaffaro R, Ginestra G, D'Arrigo M, Botta L, Marino A, Bisignano $G$ (2010) Control of biofilm formation by polyethyleneco-vinyl acetate films incorporating nisin. Appl Microbiol Biotechnol 87:729-737

Nostro A, Scaffaro R, D'Arrigo M, Botta L, Filocamo A, Marino A, Bisignano G (2012) Study on carvacrol and cinnamaldehyde polymeric films: mechanical properties, release kinetics and antibacterial and antibiofilm activities. Appl Microbiol Biotechnol. doi:10.1007/s00253-012-4091-3

Oh WK, Kim S, Yoon H, Jang J (2010) Shape-dependent cytotoxicity and proinflammatory response of poly(3,4-ethylenedioxythiophene) nanomaterials. Small 6:872-879

Perale G, Casalini T, Barri V, Müller M, Maccagnan S, Masi M (2010) Lidocaine release from polycaprolactone threads. Appl Polym Sci 117:3610-3614

Pollini M, Russo M, Licciulli A, Sannino A, Maffezzoli A (2009) Characterization of antibacterial silver coated yarns. J Mater Sci Mater Med 20:2361-2366

Russell AD, Day MJ (1993) Antibacterial activity of chlorhexidine. J Hosp Infect 25:229-238

Saxena S, Ray AR, Kapil A, Pavon-Djavid G, Letourneur D, Gupta B, Meddahi-Pellé A (2011) Development of a new polypropylene-based suture: plasma grafting, surface treatment, 
characterization, and biocompatibility studies. Macromol Biosci 11:373-382

Scaffaro R, Botta L, Marineo S, Puglia AM (2011) Incorporation of nisin in poly (ethylene-co-vinyl acetate) films by melt processing: a study on the antimicrobial properties. J Food Prot 74:1137-1143

Scaffaro R, Botta L, Gallo G (2012) Photo-oxidative degradation of poly(ethyleneco-vinyl acetate)/nisin antimicrobial films. Polym Degrad Stab 97:653-660
Teo EY, Ong S-Y, Khoon Chong MS, Zhang Z, Lu J, Moochhala S, Ho B, Teoh S-H (2011) Polycaprolactone-based fused deposition modelled mesh for delivery of antibacterial agents to infected wounds. Biomaterials 32:279-287

Zhukovskii VA, Khokhlova VA, Korovicheva SY (2007) Surgical suture materials with antimicrobial properties. Fibre Chem 39:136-143

Zurita R, Puiggalí J, Rodríguez-Galán A (2006) Triclosan release from coated polyglycolide threads. Macromol Biosci 6:58-69 